\title{
In vitro Bioactivities of Three Reputed Medicinal Plants of Bangladesh
}

\author{
Abu Bakar Siddique ${ }^{1}$, Ridwan Islam², Md. Al Amin Sikder ${ }^{2}$, Ridwan Bin Rashid ${ }^{3}$, \\ A.K.M. Nawshad Hossian ${ }^{1}$ and Mohammad A. Rashid ${ }^{2}$ \\ ${ }^{1}$ Department of Pharmacy, State University of Bangladesh, Dhaka-1205, Bangladesh \\ ${ }^{2}$ Department of Pharmaceutical Chemistry, Faculty of Pharmacy, University of Dhaka, Bangladesh \\ ${ }^{3}$ Department of Microbiology, University of Dhaka, Dhaka-1000, Bangladesh
}

Received: March 10, 2014; $\quad$ Accepted: May 22, 2014;

Published (Web): July 23, 2014

\begin{abstract}
The study was designed to evaluate the preliminary biological activities of crude methanol extracts of the leaf of Justicia gendarussa, Sansevieria trifasciata and Hydnocarpus kurzii and their organic soluble partitionates. The polyphenol content was determined spectrophotometrically and expressed as gallic acid equivalents. The total phenolic content was found to vary for different test samples ranging from $1.45 \pm 0.25 \mathrm{mg}$ to $40.73 \pm 0.22 \mathrm{mg}$ of GAE/ gm of dried extract. The antioxidant potential was evaluated by DPPH free radical scavenging assay using butylated hydroxytolune (BHT) and ascorbic acid as standards. In the assay, the CSF of H. kurzii and the PESF of $J$. gendarussa revealed the highest free radical scavenging activity with $\mathrm{IC}_{50}$ values $3.25 \pm 0.05 \mu \mathrm{g} / \mathrm{ml}$ and $24.68 \pm$ $0.26 \mu \mathrm{g} / \mathrm{ml}$, respectively. The brine shrimp lethality bioassay was utilized to evaluate the cytotoxicity. The chloroform soluble fraction (CSF) and methanol extract (ME) of $J$. gendarussa exhibited strong cytotoxicity with $\mathrm{LC}_{50}$ values of $0.002 \mu \mathrm{g} / \mathrm{ml}$ and $0.06 \mu \mathrm{g} / \mathrm{ml}$, respectively. The membrane stabilizing activity was assessed by evaluating hemolysis of RBC in hypotonic solution and was compared with acetyl salicylic acid. On the other hand, the chloroform soluble fraction of J. gendarussa and aqueous soluble materials of $S$. trifasciata produced $75.60 \%$ and $75.0 \%$ inhibition of hemolysis of RBC, respectively as compared to $77.9 \%$ inhibited by acetyl salicylic acid $(0.10 \mathrm{mg} / \mathrm{ml})$.
\end{abstract}

Key words: Membrane stabilization, TPC, Free radical scavenging, cytotoxicity

\section{Introduction}

Justicia gendarussa Burm.f. (Bengali name: Bishjaron, Family: Acanthaceae) is a shade loving, quick growing, evergreen scented shrub found throughout India and all Asian countries like Malaysia, Indonesia, Srilanka. The plant is used in traditional medicine for chronic rheumatism, inflammations, bronchitis, vaginal discharges, dyspepsia, eye diseases and fever. Justicia species has been found to contain lignans, naturally occurring phenolic dimmers and triterpenoids (Uddin et $a l ., 2011)$. Lignans have been used as lead compounds for the development of anti rheumatic agents (Sikder et al., 2011a).

Sansevieria trifasciata prain (Bangali nameGhorchhokor, English- Powstring hemp, Mother-in-law's tongue, Family- Agavaceae) is a perennial seamless herb with erect leaves arising from an underground rhizome. Leaves are thick, flat, fibrous, and smooth in texture, up to $1 \mathrm{~m}$ long, with thin pointed apices, the blade of light green colour with small white lines running perpendicular to the growth of the leaf. Phytochemical screening of this plant has shown the presence of $N$-butyl-4-ol- $N$ propylphthalate, pregnane glycosides, and steroidal sapogenins (Yoshihrio et al., 1996). The leaf sap is applied directly to infected sores, cuts and grazes. It is also used to treat fungal infection and scabies (Traditional Medicine Database- 2002).

Hydnocarpus kurzii (King) Warb (Bangali nameChaulmoogra, Family- Achariaceae) is a tree attaining the height of 40-50 feet. Hydnocarpus oil and the crushed seed have long been used in Southeast Asia to treat various skin diseases like scabies, eczema, psoriasis, scrofula, ringworm, and intestinal worms and it has been shown that the active principles of the oil (hydnocarpic and chaulmoogric acids) are strongly antibacterial in nature. For this reason Chaulmoogra is employed in Indian medicine to treat leprosy (Oommen et al., 1999). The bark contains principles capable of reducing fevers. Seeds are usually applied externally as a dressing for skin diseases combined with walnut oil and pork lard for

Correspondence to: Mohammad A. Rashid; Tel.: +880-2-9661900, Extn. - 8137; Fax: +880-2-9667222; E-mail: rashidma@du.ac.bd 
ringworm; with calomel and sesame oil for leprosy; and with sulfur and camphor for scabies (Sikder et al., 2011b).

\section{Materials and Methods}

Plant materials: Leaves of S. trifasciata, and H. kurzii were collected from Dhaka while J. gendarussa leaves were collected from Gazipur in the month of January 2011. The voucher specimens for each of the collections (DACB 35490, 35491, and 35489, respectively) have been deposited in Bangladesh National Herbarium (BNH) for future references. The leaves were first separated from the plants, cleaned, cut into small pieces and air- dried for several days. The plant materials were then oven dried for 24 hours at $40^{\circ} \mathrm{C}$ and ground to a coarse powder. The powdered materials (300 gm each) were then soaked in methanol (1.5 liter each) and kept for 10 days at room temperature with occasional shaking. The crude extracts were then filtered through cotton plug followed by Whatman no. 1 filter paper and the extracts were concentrated with rotary evaporator. Each of concentrated methanol extracts were partitioned (Van Wagenen et al., 1993) and the resultant partitionates i.e., pet-ether (PESF), carbon tetrachloride (CTCSF), chloroform (CSF), and aqueous (AQSF) soluble fractions (Table 1) were used for the experimental processes.

Table 1. Different partitionates of $J$. gendarussa, $S$. trifasciata, $H$. kurzii, obtained by Kupchan partitioning from $5 \mathrm{~g}$ of crude extract.

\begin{tabular}{lccc}
\hline Partitionates & $\begin{array}{c}\text { J. gendarussa } \\
(\mathrm{g})\end{array}$ & $\begin{array}{c}\text { S. trifasciata } \\
(\mathrm{g})\end{array}$ & $\begin{array}{c}\text { H. kurzii } \\
(\mathrm{g})\end{array}$ \\
\hline PTSF & 1.2 & 1.4 & 1.0 \\
CTSF & 0.6 & 0.6 & 0.6 \\
CSF & 0.5 & 0.5 & 0.8 \\
AQSF & 1.2 & 1.1 & 1.4 \\
\hline
\end{tabular}

$\mathrm{PESF}=$ Pet-ether soluble fraction of methanolic extract, $\mathrm{CTSF}=$ Carbon tetrachloride soluble fraction of methanolic extract, $\mathrm{CSF}=\mathrm{Chloroform}$ soluble fraction of methanolic extract, $\mathrm{AQSF}=$ Aqueous soluble fraction of methanolic extract.

Membrane stabilizing activity: The membrane stabilizing activity of the extractives was determined by their ability to inhibit heat and hypotonic solution induced haemolysis of human erythrocytes following the method developed by Omale et al. in 2008.
Total phenolics analysis: Total phenolic content: The total phenolic content (TPC) of the extractives was determined with Folin Ciocalteau reagent by using the method developed by Harbertson and Spayd (2006).

Free radical scavenging activity: Following the method developed by Brand-Williams et al. (1995), the antioxidant activity of the test samples was assessed by evaluating the scavenging activities of the stable 1,1diphenyl-2-picrylhydrazyl (DPPH) free radical by using synthetic antioxidants, butylated hydroxytoluene (BHT) and ascorbic acid as positive controls.

Brine shrimp lethality bioassay: This technique was applied for the determination of general toxic properties of the DMSO solutions of plant extractives against Artemia salina in a one day in vivo assay (Meyer et al., 1982). Vincristine sulphate was used as positive control.

Statistical analysis: Three replicates of each sample were used for statistical analysis and the values are reported as mean $\pm \mathrm{SD}$.

\section{Results and Discussion}

The present study was undertaken to evaluate the membrane stabilizing, free radical scavenging and cytotoxic properties of different organic soluble materials of the methanolic extract of $J$. gendarussa, $S$. trifasciata and H. kurzii.

The extractives of $J$. gendarussa, S. trifasciata and $H$. kurzii at $2.0 \mathrm{mg} / \mathrm{ml}$ significantly protected the lysis of mice erythrocyte membrane induced by hypotonic solution as compared to the standard acetyl salicylic acid $(0.10 \mathrm{mg} / \mathrm{ml})$ (Table 2). The chloroform soluble fraction of $J$. gendarussa inhibited $75.60 \%$ and aqueous soluble fraction of S. trifasciata produced $75.0 \%$ inhibition of hemolysis of RBC as compared to $77.9 \%$ revealed by acetyl salicylic acid $(0.10 \mathrm{mg} / \mathrm{ml})$. At the same time aqueous soluble fraction of $J$. gendarussa, chloroform soluble fraction of $S$. trifasciata and carbon tetrachloride, chloroform, and aqueous soluble fractions of $H$. kurzii revealed $71.93 \%, \quad 72.7 \%, 70.56 \%, \quad 70.24 \%, \quad 69.45 \%$ inhibition, respectively.

The total phenolic content was found to vary for different test samples ranging from $1.45 \pm 0.25 \mathrm{mg}$ to $40.73 \pm 0.22 \mathrm{mg}$ of GAE/ $\mathrm{g}$ of dried extract (Table 3 ). In S. trifacicata the highest total phenolics was found in PESF ( $40.73 \pm 0.22 \mathrm{mg}$ of GAE/g of dried extract) and the 
lowest in AQSF $(1.45 \pm 0.25 \mathrm{mg}$ of $\mathrm{GAE} / \mathrm{g}$ of dried extract), whereas, in J. gendarussa the highest total phenolics was found in PESF $(38.89 \pm 0.22 \mathrm{mg}$ of GAE/ $\mathrm{g}$ of dried extract) and the lowest in CTSF $(6.29 \pm 0.16 \mathrm{mg}$ of GAE/g of dried extract) and in case of $H$. Kurzii the highest phenolics was found in AQSF (12.69 $\pm 0.14 \mathrm{mg}$ of GAE/g of dried extract). The antioxidant potential was evaluated by DPPH free radical scavenging assay using butylated hydroxytolune (BHT) and ascorbic acid as standards. In the assay, the CSF of H. kurzii and the PESF of $J$. gendarussa revealed the highest free radical scavenging activity with $\mathrm{IC}_{50}$ values $3.25 \pm 0.05 \mu \mathrm{g} / \mathrm{ml}$ and $24.68 \pm 0.26 \mu \mathrm{g} / \mathrm{ml}$, respectively (Table 3 ).

In the brine shrimp lethality bioassay, chloroform extract of $J$. gendarussa showed strong cytotoxic activity with $\mathrm{LC}_{50}$ value of $0.002 \mu \mathrm{g} / \mathrm{ml}$. The MEF exhibited significant lethality having $\mathrm{LC}_{50}$ value of $0.06 \mu \mathrm{g} / \mathrm{ml}$ while the PESF, CTSF and AQSF demonstrated cytotoxic activity against shrimp nauplii with $\mathrm{LC}_{50}$ values of 0.5 ,

Table 2. Effect of extractives of $H$. Kurzii, S. trifacicata, J. gendarussa on hypotonic solution-induced hemolysis of erythrocyte membrane

\begin{tabular}{lccc}
\hline \multicolumn{3}{c}{ \% Inhibition of hemolysis } \\
\hline $\begin{array}{l}\text { Sample } \\
\text { code }\end{array}$ & J. gendarussa & S. trifacicata & H. Kurzii \\
\hline MEF & $41.82 \pm 0.22$ & $14.05 \pm 0.28$ & $14.56 \pm 0.33$ \\
PESF & $41.78 \pm 0.28$ & $52.91 \pm 0.28$ & $40.04 \pm 0.22$ \\
CTSF & $53.17 \pm 0.22$ & $38.52 \pm 0.23$ & $70.56 \pm 0.39$ \\
CSF & $75.60 \pm 0.45$ & $72.71 \pm 0.17$ & $70.24 \pm 0.23$ \\
AQSF & $71.93 \pm 0.17$ & $75.00 \pm 0.13$ & $69.45 \pm 0.17$ \\
ASA & \multicolumn{4}{c}{77.9} \\
\hline
\end{tabular}

Table 3. Total phenolic content, free radical scavenging and cytotoxic activities of different partitionates of $H$. Kurzii, $S$. trifacicata, J. gendarussa.

\begin{tabular}{|c|c|c|c|}
\hline \multirow[t]{2}{*}{ Sample code } & $\begin{array}{l}\text { Total phenolic content (mg of GAE/ } \\
\text { g of dried extract) }\end{array}$ & $\begin{array}{l}\text { Free radical scavenging activity } \\
\qquad\left(\mathrm{IC}_{50} \mu \mathrm{g} / \mathrm{ml}\right)\end{array}$ & Cytotoxic activity $\left(\mathrm{LC}_{50} \mu \mathrm{g} / \mathrm{ml}\right)$ \\
\hline & \multicolumn{3}{|c|}{ J. gendarussa } \\
\hline MEF & $11.41 \pm 0.19$ & $28.41 \pm 0.21$ & $0.06 \pm 0.01$ \\
\hline PESF & $38.89 \pm 0.22$ & $24.68 \pm 0.26$ & $0.5 \pm 0.01$ \\
\hline CTSF & $6.29 \pm 0.16$ & $41.21 \pm 1.0$ & $1.32 \pm 0.01$ \\
\hline AQSF & $18.53 \pm 0.23$ & $59.84 \pm 0.15$ & $1.37 \pm 0.32$ \\
\hline \multirow[t]{2}{*}{$\mathrm{CSF}$} & $7.60 \pm 0.19$ & -- & $0.002 \pm 0.00$ \\
\hline & \multicolumn{3}{|c|}{ S. trifacicata } \\
\hline MEF & $12.50 \pm 0.12$ & $59.93 \pm 0.30$ & $0.89 \pm 0.12$ \\
\hline PESF & $40.73 \pm 0.22$ & $48.77 \pm 0.18$ & $1.09 \pm 0.11$ \\
\hline CTSF & $5.07 \pm 0.16$ & $80.53 \pm 0.27$ & $3.19 \pm 0.72$ \\
\hline AQSF & $1.45 \pm 0.25$ & $138.35 \pm 0.26$ & $3.62 \pm 1.56$ \\
\hline \multirow[t]{2}{*}{$\mathrm{CSF}$} & $11.08 \pm 0.22$ & -- & $0.31 \pm 0.01$ \\
\hline & \multicolumn{3}{|c|}{ H. Kurzii } \\
\hline MEF & $9.33 \pm 0.14$ & $251.73 \pm 1.90$ & $1.90 \pm 0.36$ \\
\hline PESF & $5.11 \pm 0.13$ & $64.41 \pm 0.92$ & $8.73 \pm 2.12$ \\
\hline CTSF & $12.05 \pm 0.12$ & $30.91 \pm 0.49$ & $0.33 \pm 0.05$ \\
\hline CSF & $8.57 \pm 0.22$ & $3.25 \pm 0.05$ & $0.25 \pm 0.02$ \\
\hline AQSF & $12.69 \pm 0.14$ & $40.78 \pm 0.44$ & $5.87 \pm 1.11$ \\
\hline VS & -- & -- & $0.451 \pm 0.004$ \\
\hline BHT & -- & $27.5 \pm 0.54$ & -- \\
\hline ASA & -- & $5.8 \pm 0.21$ & -- \\
\hline
\end{tabular}

1.32 and $1.37 \mu \mathrm{g} / \mathrm{ml}$, respectively. The carbon tetrachloride and chloroform soluble partitionates of $H$. Kurzii showed potential cytotoxic activity with $\mathrm{LC}_{50}$ values of 0.25 and $0.33 \mu \mathrm{g} / \mathrm{ml}$, respectively while the MEF, AQSF and PESF demonstrated moderate activity against shrimp nauplii with the $\mathrm{LC}_{50}$ values of $1.90,5.87$ and $8.73 \mu \mathrm{g} / \mathrm{ml}$, respectively. Methanol and chloroform extract of $S$. trifacicata revealed strong cytotoxic activity with $\mathrm{LC}_{50}$ value of 0.31 and $0.89 \mu \mathrm{g} / \mathrm{ml}$, respectively while the PESF, CTSF, and AQSF demonstrated moderate activity against 
shrimp nauplii with the $\mathrm{LC}_{50}$ values of $1.09,3.19$ and 3.62 $\mu \mathrm{g} / \mathrm{ml}$, respectively (Table 3 ).

\section{Conclusion}

The results obtained in our studies indicate that extractives of three plants can be considered as the potential sources of bioactive compounds and natural antioxidants. Further studies are underway to isolate and characterize the compounds responsible for these activities.

\section{Acknowledgement}

The authors are grateful to the State University of Bangladesh for providing the laboratory facilities to carry out the experimental procedures.

\section{References}

Brand-Williams, W., Cuvelier, M.E. and Berset, C. 1995. Use of free radical method to evaluate antioxidant activity. Lebensm. Wiss. Technol. 28, 25-30.

Harbertson, J. and Spayd, S. 2006. Measuring phenolics in the winery. Am. J. Enol. Vitic. 57, 280-288.

Meyer, B.N., Ferrigni, N.R., Putnam, J.E., Jacobsen, J.B., Nicholsand, D.E. and Mclaughlin, J.L. 1982. Brine shrimp: a convenient general bioassay for active plant constituents. Planta Med. 45, 31-34.
Omale, J. and. Okafor, P.N. 2008. Comparative antioxidant capacity, membrane stabilization, polyphenol composition and cytotoxicity of the leaf and stem of Cissus multistriata. Afr. J. Biotechnol. 7, 3129-3133.

Oommen, S.T., Rao, M. And Raju, C.V. 1999. Effect of oil of Hytnocarpus on wound healing. Int. J. Lepr. 67, 154-156.

Sikder, M.A., Siddique, A.B., Hossian, A.K.M.N., Miah, M.K., Kaisar, M.A., and Rashid, M.A. 2011a. Evaluation of thrombolytic activity of four Bangladeshi medicinal plants, as a possible renewable source for thrombolytic compounds. J. Pharm. Nutr. Sci. 1, 4-8.

Sikder, M.A., Hossian, A.K.M.N., Siddique, A.B., Ahmed, M., Kaisar, M.A., and Rashid, M.A. 2011b. In vitro antimicrobial screening of four reputed Bangladeshi medicinal plants. Pharmacog. J. 3, 72-75.

Traditional Medicine Database. 2002. National Department of Health, Govt. of Papua New Guinea, Waigani, NCD, Papua New Guinea.

Uddin, M.R., Sinha, S., Hossain M.A., Kaiser, M.A., Hossain, M.K. and Rashid, M.A. 2011. Chemical and biological unvestigations of Justicia gendarussa (Burm.f.). Dhaka Univ. J. Pharm. Sci. 10, 53-57.

Van Wagenen, B.C., Larsen, R., Cardellina, J.H., Ran dazzo, D., Lidert, Z.C. and Swithenbank, C. 1993. Ulosantoin, a potent insecticide from the sponge Ulosa ruetzleri. J. Org. Chem. 58, 335-337.

Yoshihrio, M., Toshihiro, I., Minpei, K. and Yutaka, S 1996. Steroidal Saponins from Sansevieria trifasciata. Phytochemistry 43, 1325-1331. 